\title{
OJS

\section{ESTUDOS DA PAISAGEM NO PROCESSO ENSINO- APRENDIZAGEM À CONSTRUÇÃO DO SABER GEOGRÁFICO NO ENSINO MÉDIO DA EDUCAÇÃO BÁSICA}

\author{
Hudson Nascimento de Sousa Filho', Reges Sodré da Luz Silva Dias² \\ ${ }^{1}$ Geógrafo. Membro atuante em Ensino, Pesquisa e Extensão no Laboratório de Estudos Agrários e Direitos \\ Humanos (LEADH) e no Laboratório de Estudos das Dinâmicas Territoriais na Amazônia (LEDTAM), E-mail: \\ hnascimento329@gmail.com \\ ${ }^{2}$ Graduado em Geografia, Licenciatura, pela Universidade Federal do Tocantins (2014). Mestrado em Geografia \\ pela Universidade Federal de Uberlândia (2016). Doutorando em Geografia pelo IESA/UFG. E-mail: \\ reges@mail.uft.edu.br; https://orcid.org/0000-0002-9615-528X
}

Artigo recebido em 09/04/2020 e aceito em 22/08/2020

\begin{abstract}
RESUMO
Esse artigo tem por objetivo relatar a construção de metodologias libertadoras no processo ensino-aprendizagem de Geografia durante a realização da disciplina de Estágio Supervisionado no Ensino Médio da educação escolar básica na cidade de Araguaína-TO. Propomos apresentar a metodologia de análise em geossistema da paisagem produzida por Georges Bertrand (2004), como recurso auxiliar no entendimento de determinados problemas/conteúdos ambientais geográficos. Entendemos que a(s) paisagem(ns) apresentam-se ou/e por nós podem ser apreendidas como verdadeiras heranças da fusão de processos pretéritos com processos da história do presente. Tal metodologia pôde ser exemplificada no tratamento da paisagem do córrego do prata, localizado próximo da escola e que os alunos conheciam. Este córrego teve sua dinâmica natural remodelada para nós, gerações do presente, enquanto herança. Antes as pessoas banhavam sem o medo de serem atropeladas quando iam acessar as águas do córrego. Ou quando havia muito mais peixes para pescar do que hoje. Ou quando as águas do córrego não eram poluídas pelo lixo e demais dejetos gerados por pessoas que trafegam nas vias da BR-153 com seus veículos automotivos.
\end{abstract}

Palavras-Chave: metodologia; paisagem; ensino.

\section{LANDSCAPE STUDIES IN THE TEACHING-LEARNING PROCESS TO BULDING GEOGRAPHICAL KNOWLEDGE IN BASIC EDUCATION}

\begin{abstract}
This article aims to report the construction of liberating methodologies in the teaching-learning process of Geography during the accomplishment of the Supervised Internship in the Secondary Shool of Araguaína-TO. We propose to present the geosystem analysis methology of landscape produced by Georges Bertrand (2004), as an auxiliary resource in the understanding of certain geographic environmental problems/contentes. We understand that the landscape(s) present themselves or/and we can be apprehended as true inheritances of the fusion of past processes with processes of the history of the presente. Such methodology could be exemplified in the treatment of the silver stream landscape, located near the school and which the students knew. This stream has dad its natural dynamics reshaped for us present generations as inheritance. Before people bathed without the fear of being run over when they went to access the waters of the stream. Or when there were a lot more fish to take than today. Or
\end{abstract}


when the stream's waters were not polluted by rubbish and other waste generated by people traveling on the BR153 roads with their automotive vehicles.

Keywords: methodology; landscape; teaching.

\section{DIÁLOGO INTRODUTÓRIO}

Este artigo tem por objetivo apresentar nossas experiências advindas da realização da disciplina de Estágio Supervisionado no Ensino Médio - Universidade Federal do Tocantins, desenvolvido de forma teórico-prática na escola-campo Colégio Estadual Campos Brasil, localizado no setor Bairro de Fátima, cidade de Araguaína-TO. Aonde realizamos 18 encontros, em turno matutino geralmente no horário de 07:00 às 11:20 horas, distribuídos entre os dias de 16 ao dia 31 do mês de Outubro do ano de 2018, na série do primeiro ano do ensino médio turmas A, B e C.

Nossa prática pedagógica na sala de aula, durante esse período, procurou ser construída de forma pedagógica dialógica libertadora e também crítico-social dos conteúdos. Na "[...] perspectiva de que os educandos adquiram consciência política de sua situação e de suas possibilidades de reação e luta contra a sociedade que oprime [...]". Adicionalmente está "[...] preocupada com a perspectiva de elevação cultural dos educandos a partir da articulação entre o mundo vivido e a cultura elaborada [...]”. (LUCKESI, 1994, p. 154-155).

Escolheu-se essa orientação em virtude da realidade encontrada no espaço escolar desde o primeiro estágio, iniciado no segundo semestre do ano de 2017 na escola. Durante esse período foi comum ouvir nos corredores da escola-campo que estagiamos, ou em sala de aula, ou até mesmo na sala dos professores o discurso de que os jovens de hoje não querem "nada" com a vida nem se quer estudar! Isso nos levou a levantar os seguintes questionamentos, será que as atuais didáticas da educação escolar ${ }^{1}$ construídas no planejamento e desenvolvimento construtivo das aulas dialogam com os estudantes no que confere em alcançar estes em termos de construção do(s) conteúdo(s) estudado(s)? Será que a didática está sendo considerada como "teoria do ensino" de auxílio à pedagogia enquanto ciência para estudo da educação, da instrução e do ensino?

Consideramos o processo de ensino como objeto de estudo da didática, na medida em que a educação é socialmente determinada. Ressaltando, tendo como base Libâneo (2006, p.

\footnotetext{
1 "A educação escolar constitui-se num sistema de instrução e ensino com propósitos intencionais, práticas sistematizadas e alto grau de organização, ligado intimamente às demais práticas sociais." (LIBÂNEO, 2006, p. 24).
} 
15-31), o fato de que a "ação pedagógico-didática" entende-se em nosso trabalho como "mediação entre as bases teórico-científicas da educação escolar e a prática docente". O que não presenciamos sendo praticado atualmente no contexto escolar público araguainensebrasileiro por não atribuir ao ensino da educação escolar "o entendimento crítico dos problemas sociais" mediados na própria vida dos alunos.

Essas reflexões mais amplas do campo educacional, encontra ressonância, ainda que restrita, na geografia. Nesse sentido, para Vesentini (2010, p. 37) devemos construir a geografia, geógrafos e professores. Para ele, "isso não deve significar elaborar um modelo a ser seguido (de métodos, termos, conceitos, sequências da apresentação, etc.), pois o modelo por si mesmo destrói a criatividade, limita a descoberta do novo" e "transforma o conhecimento de fundante em fundado". Pelo contrário, significa "que a geografia se fará diferente de acordo com o problema enfrentado e o engajamento do sujeito do conhecimento". Assim, "o educando pode tornar-se co-autor do saber (com os estudos do meio participativos, debates frequentes, textos e conteúdo adequados à realidade social e existencial dos alunos, etc.)”.

Essa revisão teórica se realizou em diálogo com uma análise de forma crítica e espacial dos currículos-formais por nós utilizados no/para o processo ensino-aprendizagem à construção do saber geográfico em sala para com os estudantes envolvidos no processo. Logo sendo a Proposta Curricular do Ensino Médio: versão preliminar - escolas do Tocantins (PCEM - TO), em nível regional e, de nível referencial nacional, a proposta da nova Base Nacional Comum Curricular para o ensino médio (BNCC - EM) - aqui consultadas.

Uma primeira constatação é que há completa ausência teórico-metodológica na abordagem categórica e conceitual - da paisagem, aqui em nosso caso de estudo. Havendo apenas indicações do que pode ser esta mas ao mesmo tempo com certo teor de negligência da prática teórica e metodológica da didática de como trabalhá-la no ensino médio da educação básica do Estado do Tocantins. Isso começa pela proposta de conteúdos que o referencial apresenta para estudo das esferas ambientais, apontando que este estudo seja desenvolvido com olhar especializado, apenas, unilateral sobre elementos físicos da natureza, parte apenas do processo total, como: "litosfera, hidrosfera, atmosfera e biosfera" (BRASIL, 2009, p. 277). Uma divisão de áreas especializadas que não corresponde ao ensino de geografia mediante a leitura das paisagens "impressas" da e na dinâmica espacial-histórica ao ponto que, se correspondem, é para acentuar mais e mais a velha interpretação mnemônica e decorativa que 
nos afundam cada vez mais a um dado olhar apenas descritivo perante à paisagem. Logo também ao espaço geográfico.

Sendo que, por não haver uma visão didática à construção do saber para apreensão do espaço geográfico por mediação da categoria paisagem - o que acarreta, a nosso ver como exemplo de nossas experiências, na ausência de uma abordagem dos conteúdos com conceitos construídos da interpretação teórica que as categorias geográficas de análise do espaço geográfico podem proporcionar e propiciam -, acaba ocorrendo o fato de que a linguagem propriamente geográfica de estudo e ensino-aprendizagem em Geografia na educação escolar é negligenciada. Ou seja, os conteúdos que deveriam ser abordados a partir de conceitos compreendidos com intermédio da categoria paisagem não os são na medida em que a "[...] relação sociedade, natureza e cultura foi selecionada como uma categoria analítica da Geografia por estabelecer relações com todos os conteúdos da referida disciplina" (BRASIL, 2009, p. 269).

Restando, o que seria metaforicamente uma "luz" a ser seguida, - mesmo ainda que muito disperso e pouco fundamentado no sentido da ausência explicita de parâmetros não apenas "conteudistas" mas também teórico-metodológicos de como se abordar a paisagem no ensino geográfico da educação escolar para interpretação e compreensão de determinados conteúdos -, a sugestão de construirmos como habilidade no ensino: “comparar os principais usos e formas de ocupação dos diversos domínios naturais e suas implicações sócio-ambientais”. (BRASIL, 2009, p. 277).

Vale notar que a palavra paisagem se quer foi digitada entre as milhares visíveis na estrutura textual da nova BNCC - Base Nacional Curricular Comum, apresentada como proposta curricular-formal ao ensino médio. Há uma verdadeira separação da relação sociedade e natureza e essa separação ocorre pois "a base" aponta com teor eufêmico que a sociedade age com "consciência" na relação sociedade-natureza. Inexistente justamente devido a inexistência de uma linguagem geográfica de fato para estudo dos dados conteúdos. A metodologia cabível para estudo - e que por sinal defendemos aqui como alternativa para fuga desse quadro catastrófico - não só é negada como substituída por certa "abordagem" abstrata da realidade; e justamente nesta abstração abre-se vaga para atuação da inexistente consciência humana na relação sociedade-natureza, grosso modo. Que pode ser contrária se analisada de forma crítica e espacial. E não apenas ideal; ora a poluição ambiental não é uma ação consciente e abstrata tão pouco inexiste. 
[...] Essa realidade é uma totalidade que envolve sociedade e natureza. Cabe à geografia levar a compreender o espaço produzido pela sociedade em que vivemos hoje, suas desigualdades e contradições, as relações de produção que nela se desenvolvem e a apropriação que essa sociedade faz da natureza. (OLIVEIRA, 2010, p. 142).

Ou seja: na macro-área - aqui chamamos assim a área de Ciências Humanas e Sociais Aplicadas (CHSA) da BNCC - o estudo geográfico de fato é negligenciado ao ponto que apenas suas categorias: espaço e território são expostas para análise da realidade social e do movimento espacial geográfico. E, em termos gerais, esta macro-área aponta que, para abordagem dos conteúdos das CHSA's, seja adotada a compreensão basilar de que:

\begin{abstract}
As relações entre sociedade e natureza em diferentes culturas, sua organização social, política e cultural, suas formas de trabalho, suas relações com outras populações e seus conflitos e negociações permitem compreender seus significados, ultrapassando o campo das evidências e caminhando para o campo das representações abstratas. (BRASIL, 2016, p. 550).
\end{abstract}

Verdadeiro currículo falacioso, que intencionalmente, obedecendo leis econômicas gerais para/de confusão da educação, ressalta ainda que:

Todavia, os humanos têm, também, necessidades relacionadas à sua sobrevivência. Nesse sentido, exercem atividades que implicam relações com a natureza, agindo sobre ela de maneira deliberada e consciente, transformando-a. O processo dessa atividade, desse trabalho, permite ao indivíduo produzir-se como ser social. (BRASIL, 2016, p. 553).

Como crítica central ressaltamos que a BNCC (BRASIL, 2016) reforça a consciência abstrata de exteriorização do ser (da cultura) como elemento não pertencente à natureza total. Advinda, acreditamos nós, de uma herança ocidental atrelada a um conceito de natureza não natural (GONÇALVES, 1990). Emergente à dominação do homem sobre a natureza (não entendendo esta constituída como um todo aonde a sociedade é parte) e sobre a diferença. Pois, a partir de tais princípios o homem: branco, rico e "ocidental", na maioria dos casos, torna-se dominador de tais recursos e logo produtor de mais, e cada vez mais, riquezas exteriorizando a cultura da natureza. Quebrando a junção do conjunto que em suma podemos entender como meio ambiente.

Reforçando tal colocação, enfatiza Gonçalves (1990, p. 23) que toda: 
[...] sociedade, toda cultura cria, inventa, institui uma determinada ideia do que seja natureza. Nesse sentido o conceito de natureza não é natural, sendo na verdade criado e instituído pelos homens. Constitui um dos pilares através do qual os homens erguem as suas relações sociais, sua produção material e espiritual, enfim, a sua cultura.

Contrariamente ao modo puramente abstrato e sem sentido educacional; e sem direção metodológica e que tenta empurra-se "goela a baixo" do nosso sistema escolar de ensino de Geografia, com a semiologização (idealista) da realidade de interpretação e investigação social em discurso esfacelado de representação absoluta de estado para o "além" da modernidade visto na BNCC em estudo da relação “indivíduo, natureza, sociedade, cultura e ética” (BRASIL, 2016, p. 553). Propomos uma discussão mediada pela leitura da totalidade espacial geográfica consoante à "produção material da vida imediata e na concepção da forma de intercâmbio intimamente ligada a esse modo de produção e por ele produzida" em que "as circunstâncias fazem os homens tanto quanto os homens fazem as circunstâncias" (MARX; ENGELS, 2009, p. 57-59).

Ou seja,

[...] não explica a práxis a partir da ideia, explica as formações das ideias [Ideenformationen] a partir da práxis material e chega, em consequência disso, ao resultado de que todas as formas e produtos da consciência podem ser resolvidos não pela crítica espiritual, pela dissolução na "Consciência de Si" ou pela transformação em "fantasmas", "espectros", "visões" etc., mas apenas pela subversão [Umsturz] prática das relações sociais reais de que derivam essas fantasias idealistas - a força motora da história, também da religião, da filosofia e de toda as demais teorias, não é a crítica, mas a revolução. (MARX; ENGELS, 2009, p. 58).

Não trabalhamos a partir de uma práxis separada da consciência - e que de forma falaciosa inocenta a ação antrópica do sistema capitalista de predação da natureza como vê-se na BNCC (2016), a pouco - mas sim produtora e responsável por mudar (revolucionar) a consciência de si em relação dialética do "espírito" com a formação de processos superiores ${ }^{2}$

\footnotetext{
${ }^{2}$ Segundo o pensamento de Vygotsky: estes processos tem sua origem mediante fenômenos sociais e constatam que os processos mentais compreendem-se pelo estudo da mediação de instrumentos e signos, responsáveis pela representação na relação entre o homem e o ambiente por meio do pensamento. São processos engendrados socioculturalmente mediados por signos historicizados sob técnicas na sociedade. Essa interação se faz possível pelos diversos significados expressos no contexto socioespacial onde ocorre certa mediação para formulação dos processos psicológicos superiores. Aqui o processo de educação ocorre por mediação semiótica responsáveis pela consolidação dos processos mentais superiores, destarte, a complexidade dessas relações advêm de uma série de transformações qualitativas. Estas, por sua vez, são sócio-históricas pois resultado de uma série de interações relacionais, históricas e espaciais, materialistas e dialéticas, fruto da desenvoltura cultural de uma certa sociedade. Logo, aqui, a Zona de Desenvolvimento Proximal (ZDP) estabelece-se na distância entre a zona real, e a potencial. Essa zona define-se por funções que não amadureceram, ou seja, precisam de estímulos relacionais que serão mediados por signos para o desenvolvimento de processos superiores. As funções aqui empregadas estão aptas e
} 
em meio sócio-histórico para construção do pensamento crítico. Método dialético de investigação e explicação da dinâmica espacial da materialidade histórica com que a sociedade exterioriza-se (relacionando-se ao mesmo tempo com) do que chama "natureza" ao ponto que a destrói em ação fatídica de materialidade existente e não puramente inocente e/ou abstrata.

Propomos, inspirado nesse quadro teórico ora esboçado, não um modelo pronto de como trabalhar a paisagem no ensino de geografia de primeiro ano do ensino médio da educação básica mas: (1) apresentar a metodologia de análise em geossistema da paisagem produzida por Georges Bertrand (2004), como recurso auxiliar no entendimento de determinados problemas/conteúdos ambientais geográficos; (2) alertar para compreendermos que a(s) paisagem(ns) apresentam-se ou/e por nós podem ser apreendidas como verdadeiras heranças da fusão de processos pretéritos com processos da história do presente - e que influenciarão na dinâmica de processos futuros - da interação de elementos fitogeográficos e morfoclimáticos frente o atual quadro capitalista de ação antrópica predatória; verdadeiras ecologias que na realidade herdamos para plenitude dos territórios de nossos povos e comunidades (AB'SÁBER, 2012).

Essa proposta, de modo central, estruturou-se na tentativa de buscarmos uma forma de romper com a lógica físico-descritiva de tratamento dos conteúdos que, estudados a partir da mediação didática da categoria paisagem na construção de conceitos que ajude-nos interpretar e compreender tais conteúdos, apresentam-se enquanto estudo das relações socio-ambientais presentes na formação do espaço geográfico.

[...] Com efeito, o geossistema é um complexo essencialmente dinâmico mesmo em um espaço-tempo muito breve, por exemplo, de tipo histórico. O "climax" está longe de ser sempre realizado. O potencial ecológico e a ocupação biológica são dados instáveis que variam tanto no tempo como no espaço. [...] (BERTRAND, 2004, p. 147).

Embasamento teórico-metodológico que trabalhamos em aulas estruturadas em etapas sendo que cada etapa foi dividida em dois encontros/datas. Primeira etapa: encontros nos dias de 16 e 17 de Outubro de 2018; segunda etapa: encontros nos dias de 23 e 24 de Outubro de

cheias de possibilidades para construção de estruturas cognitivas por intermédio sócio-histórico, onde a pedagogia tem um espaço sensível para atuação educacional. A ZDP nos aponta a ideia de que o desenvolvimento cognitivo apropria-se e internaliza elementos educativos do entorno sociocultural, voltando-se para uma avaliação e aprendizagem pautadas em uma aproximação com o contexto ao qual a/o estudante está inserida/o. Trazendo para o ensino básico em sala de aula uma aproximação abordada a partir de elementos percebidos e vividos em suas diversas espacialidades da relações políticas locais. (COUTINHO, 1992; SOUZA, 2011). 
2018 e; Terceira etapa: encontros nos dias de 30 e 31 de Outubro do ano de 2018. Conforme veremos em seguida, ao discorremos sobre nossas experiências teóricas e práticas na construção de metodologias libertadoras no processo ensino-aprendizagem para cumprimento da disciplina de Estágio Supervisionado no ensino médio da educação escolar básica.

\section{ESTUDOS DA PAISAGEM NO PROCESSO ENSINO-APRENDIZAGEM À CONSTRUÇÃO DO SABER GEOGRÁFICO NO ENSINO MÉDIO DA EDUCAÇÃO BÁSICA}

Seguindo a interpretação proposta pela leitura assídua dos currículos-formais e livros didáticos e demais materiais governamentais de parâmetros para educação básica, no que refere-se à construção do saber geográfico através do ensino escolar, podemos dizer que hoje no nosso caso nos deparamos mais com estudos de hidrologia do que propriamente de hidrografia - subdisciplina da Geografia que preocupa-se em investigar características especificas das águas do planeta; ora nem mesmo o sentido da produção do espaço geográfico é ensinado na educação básica a partir de seu caráter crítico-espacial-relacional. Capaz de apreender a dinâmica espacial com apoio cabível da leitura de suas categorias de análise: paisagem, lugar, região e/ou território. Como é o caso aqui trabalhado em que este ensino apresentou-se substituído por breves "pinceladas" rápidas sobre conteúdos especializados que não refletem e nem preocupam-se em engendrar certo estudo geográfico de fato dos conteúdos.

Dito isto pois, como experiência obtida neste estágio, deparamo-nos com incertezas aterrorizantes quanto aos conteúdos (e com a falta do diálogo de como ensiná-los: uma metodologia teórica e prática) propostos - tanto pelos currículos formais quanto pelo livro didático - na disciplina de Geografia a ser desenvolvida no $1^{\circ}$ ano do ensino médio do sistema educacional escolar. É o caso de nosso contexto escolar brasileiro em que o ensino de Geografia é substituído pela Hidrologia para o estudo da distribuição e escassez da água na terra, das bacias hidrográficas no Brasil ora também das bacias hidrográficas do São Francisco, amazônica e Tocantins-Araguaia. E que com muito esforço tentamos reverter com a inserção da metodologia aqui discutida e proposta.

Os conteúdos de hidrografia apresentam-se limitados em temas a serem estudados como relações socioambientais de uso da água pautados na investigação de: 1) "principais conceitos de hidrografia"; 2) "principais bacias hidrográficas do Brasil e do mundo"; 3 ) “a disponibilidade 
e os usos dos recursos hídricos" (mas apenas através da leitura quantitativa de estatísticas e percentuais de disponibilidade global das águas). (GOETTEMS; JOIA, 2016, p. 110-135). O que caracteriza como estudo especializado de hidrologia por não se ater a incitar certa discussão da relação crítica e espacial do processo de humanização da natureza ${ }^{3}$. Ora frisando dialogar a respeito do consumo abusivo da natureza na era global capitalista.

Para o estudo aqui proposto abdicamos estas concepções do determinismo geográfico de "espírito físico-descritivo" que atribui ao saber geográfico a "função ideológica" de “fotografar o espaço" (CARVALHO, 2010, p. 81-82), e levamos em consideração:

[...] a visão de que as paisagens devem ser encaradas como verdadeiros laboratórios, onde as marcas de processos pretéritos se farão presentes, entrarão em choque com processos atuais e determinarão processos futuros. Assim a dinâmica destas paisagens vai sendo retrabalhada e modificada, determinando novas características físicas. A isto chamamos de dinâmica geográfica e enxergamos no ser humano e suas contradições as grandes forças (não exclusivas) que intervêm e atuam nestes processos. Por isto ele é histórico e sua caracterização possibilita ao estudante uma visão de si, explicitando até mesmo a capacidade que ele tem ou não de intervir nessa dinâmica. (CARVALHO, 2010, p. 99. Grifos nosso).

Para nossa experiência em sala de aula tomar a paisagem como "verdadeiro laboratório" aplicou-se no tentar fazer com que os estudantes se integrassem como elementos da problemática que estudamos. Aqui damos carga teórica e conceitual do que significa não desperdiçar água ou até mesmo não poluir os rios e lagos. Pois estamos poluído a nós mesmos em sentido geral de que somos parte integrante do meio/organismo vivo terra. Conceituação de paisagem atribuída ao estudo dos conteúdos discutidos durante nosso estágio que serviu de forma ímpar na formação da consciência de que a sociedade é responsável pelas mudanças radicais que prejudicam a natureza e que tais ações, se não revistas, nos prejudicarão mais ainda no futuro como já tem por muito assolado sociedades por não estarmos exteriorizados deste contexto total.

Dinâmica que se discute com referência às ações do presente e não somente históricas como retrata o autor na citação passada ao referir-se do "choque" entre ações pretéritas e presentes que vislumbram certa perspectiva de futuro. Mas sobretudo espacial quando levamos a cargo a construção do espaço na dinâmica social agora.

\footnotetext{
${ }^{3}$ Cf. Vesentini (2010, p 35).
} 
Ainda retomando a metodologia proposta por Georges Bertrand (2004, p. 141) seria compreender que:

[...] paisagem não é a simples adição de elementos geográficos disparatados. É, em uma determinada porção do espaço, o resultado da combinação dinâmica, portanto instável, de elementos físicos, biológicos e antrópicos que, reagindo dialeticamente uns sobre os outros, fazem da paisagem um conjunto único e indissociável, em perpétua evolução. [...] não se trata somente da paisagem "natural" mas da paisagem total integrando todos as implicações da ação antrópica.

Analisar a paisagem a partir do "geossistema" (BERTRAND, 2004) nos abre um leque de possibilidades de estudo e compreensão do espaço geográfico. Possibilidades que vão adiante da velha leitura estável e descritiva do acontecer espacial. Mostra-nos que este é dinâmico e que a paisagem, como bem retrata Bertrand (2004, p. 141), nos possibilita certa leitura dialética desta situação para além da descrição dos elementos físicos mas não dispensando estes pois apontando que situação se manifesta da relação sociedade-natureza.

Nesse leque de leituras dialéticas do espaço propostas pela análise em "geossistema" priorizamos atender à categoria paisagem como "herança":

[...] Na verdade, ela é uma herança em todo sentido da palavra: herança de processos fisiográficos e biológicos, e patrimônio coletivo dos povos que historicamente as herdaram como território de atuação de suas comunidades. [...] Num primeiro nível de abordagem, poder-se-ia dizer que as paisagens têm sempre o caráter de heranças de processos de atuação antiga, remodelados e modificados por processos de atuação recente. [...] Por sua vez, os processos remodeladores são relativamente modernos e mesmo recentes, [...]. [...] Num segundo plano de abordagem, é indispensável ressaltar que as nações herdaram fatias - maiores ou menores - daqueles mesmos conjuntos paisagísticos de longa e complicada elaboração fisiográfica e ecológica. Mais do que simples espaços territoriais, os povos herdaram paisagens e ecologias, pelas quais certamente são responsáveis, ou deveriam ser responsáveis. Desde os mais altos escalões do governo e da administração até o mais simples cidadão, todos têm uma parcela de responsabilidade permanente, no sentido da utilização não predatória dessa herança única que é a paisagem terrestre. (AB'SÁBER, 2012, p. 9-10).

Com esta introdução teórico-metodológica sobre as exponentes ideias da ciência geográfica que se propuseram a discutir que ser paisagem iniciamos nosso estágio no dia de 16 de Outubro do ano de 2018. Na premissa de criarmos uma "base crítica de orientação do nosso espírito" (MARX; ENGELS, 2009) para leitura e interpretação dos conteúdos propostos para os diálogos ocorrentes em nossos encontros. Pautada, máxime, na ideia de que os seres humanos - majoritariamente na representação de grandes instituições econômicas produtoras de ações antrópicas predatórias na maioria das vezes afim de cumprir as metas de desenvolvimento 
impostas pelo mercado capitalista - são os reais responsáveis pela devastação das paisagens e que devemos nos conscientizar para mudar nosso modo de pensamento frente esta realidade degradante de nossos ambientes. Mas alertando-nos também para questão de que as instituições e empresas multinacionais representam maior parcela da produção destas "enfermidades", pois encontram-se descompromissadas com a moral e ética de cuidado do ambiente ao ponto que priorizam o lucro absoluto acima de tudo.

Ainda tentando seguir este entendimento investigamos o que se esconde atrás das cortinas do discurso da distribuição e escassez da água na terra? Buscando compreender, como objetivo geral à primeira etapa das aulas e atividades realizadas na sala, o "espírito ideológico" velado por esse enunciado que propaga-se de forma multiescalar: local, regional, nacional e global. Como exemplificação citamos aqui o diálogo que tivemos em sala sobre a privatização da água no estado em que residimos (Tocantins). Controlada pela "maior empresa privada de saneamento do Brasil", a BRK ambiental - gerida pelo grupo multinacional "Brookfield, companhia canadense que chegou ao Brasil em 1899 e administra ativos em mais de 30 países, nos cinco continentes. Desde abril de 2017, a Brookfield ${ }^{4}$ detém 70\%" das ações da BRK ambiental ${ }^{5}$. Finalizando nossa primeira etapa a partir deste segundo encontro realizado na data de 17/10/2018, de forma mais significativa possível ao criarmos o saber de que:

[...] discurso da escassez está longe de ser neutro ou ingênuo sendo, sim, um discurso interessado. É que a tradição da economia liberal, ao contrário do que pretendia seu maior prócer, Adam Smith, não tem nada a dizer sobre a riqueza, na medida que seu conceito chave é o de escassez que, rigorosamente, é o contrário de riqueza. Afinal, riqueza é o que é abundante e não o que é escasso. Nos marcos do pensamento liberal, hoje hegemônico, a água vem sendo pensada como um bem econômico mercantil a partir do conceito de escassez. Na medida que algo é pensado (e instituído) como escasso, acredita-se, pode ser objeto de compra e venda, pode ser objeto de mercantilização, posto que ninguém compraria algo que é comum a todos por sua abundância, por exemplo, enfim como algo que está disponível enquanto riqueza para todos. Assim, o discurso da escassez, prepara a privatização da água. Mais do que isso, a produz, pois como a própria palavra indica privatizar é privar quem não é proprietário privado do acesso a um bem. Enfim, a privatização produz a escassez. (GONÇALVES, 2008, p. 6).

A partir da leitura das questões puramente descritivas apontadas no livro didático inicialmente (GOETTEMS; JOIA, 2016, p. 110-135), para segunda etapa, que realizou-se nos dias de 23 e 24 de Outubro do ano de 2018, buscamos recursos expositivos de uso de vídeo-

\footnotetext{
${ }^{4}$ Saiba mais em: $<$ https://www.brookfield.com/pt-br $>$.

${ }^{5}$ Para mais informações conferir: < https://www.brkambiental.com.br/quem-somos>.
} 
documentário capaz de apontar um pouco do panorama sobre as características socioambientais das bacias hidrográficas no Brasil, na aula do dia 23. Retornado ao segundo encontro da segunda etapa (dia de 24 de Outubro de 2018) de nossas aulas com a proposta de entendimento, no que tange ao estudo das bacias hidrográficas, que temos a tarefa de - com a prerrogativa de conhecer a especificidade paisagística do contexto regional em que cada bacia hidrográfica citada como conteúdo está inserida -, apoiamo-nos na ideia de Ruffino e Santos (2002, p. 115) na qual:

[...] Salienta-se que, na produção do diagnóstico, não se utilizam técnicas e conceitos diferentes dos apresentados em materiais didáticos e paradidáticos oferecidos ao ensino, mas, ajustam-se ordens e reorientam-se os conceitos de maneira mais real e didática à vida local do educando/educador. Esta ferramenta pedagógica básica leva o processo de alteração de valores a resultados mais positivos e progressivos, contribuindo para a melhoria da qualidade ambiental dos indivíduos envolvidos.

Estudos que buscamos desenvolver na prerrogativa de cumprirmos com os objetivos propostos para segunda etapa de nossas aulas. Que foram eles o de (1) entender o conceito de bacia hidrográfica a partir de uma dimensão político de uso e regulação dos recursos hídricos disponíveis. E o de (2) listar as características ambientais do contexto paisagístico em que encontram-se inseridas as bacias hidrográficas brasileiras.

Na terceira e última etapa, dias 30 e 31 de Outubro do ano de 2018, trabalhamos em primeiro momento (30/10/2018) com questões mais específicas de realidades regionais de nosso país em estudo que contemplou processo de investigação do contexto político-econômico das bacias hidrográficas amazônica e do São Francisco. Mas, a cima de tudo, de contexto local indagando sobre as questões socioambientais refletidas na relação sociedade-natureza que se expressam no uso dos recursos disponíveis na região geopolítica da bacia hidrográfica Tocantins-Araguaia. Em que a discussão central se dispõe no uso das águas desta bacia para produção da monocultura, ora de soja ora de eucalipto, de lógica capitalista ao ponto que a política econômica deste seguimento - o agronegócio - torna-se responsável pela poluição das águas superficiais e subterrâneas (lenções freáticos) devido uso exacerbado de agrotóxicos em (produto/veneno/químico utilizado no controle de pragas e na morte de seres humanos que moram no campo brasileiro mas que também comem alimentos envenenados na cidade) em suas plantações. 
[...] En este sentido, se trata de conocer en última instancia, la responsabilidad asumida por todos los actores sociales, como se denomina hoy, a los que tienen que ver con la estructuración de las sociedades, y las consecuencias directas en relación con la degradación del paisaje natural y con la degradación del paisaje cultural. [...] Los resultados obtenidos expresan la necesidad de una correspondencia entre los aportes de la explicación y de la comprensión. El diálogo entre las ciencias y las humanidades es inevitable al momento de interpretar los diferentes espacios que se observan en relación con la calidad de vida material y cultural de sus habitantes. (NAVARRO, [s.d.], p. 9) ${ }^{6}$.

Sentido que fizemos questão de empregar na construção do conhecimento de aula quando buscamos sempre construir um estudo das bacias hidrográficas a partir do conceito de paisagem como resultado de interação em geossistema à interpretação de determinados espaços geográficos. Cabendo a nós, indo além das conceituações físicas de cunho puramente de saber hidrológico especializado, o emprego de uma conceituação socioespacial, pois reconhecemos que:

[...] A definição de bacia hidrográfica como unidade geográfica pertinente para atender a objetivos propostos por organizações institucionais emergentes não é apenas um reconhecimento de peso da dimensão ecológica, mas também das dimensões sociais, culturais e políticas na compreensão da complexidade dos processos ambientais. (CUNHA; COELHO, 2005, p. 71).

Durante nossas aulas a importância do uso de vídeo-documentário para estudo dos conteúdos a partir da construção de conceitos que representam a paisagem se expressou na “exposição” do conteúdo (LUCKESI, 1994, p. 128) mas, no caso aqui específico, ao nosso ver, auxiliou à construção do que podemos considerar "paisagens mentais" (LIMA, 2001, p. 24) que possivelmente ajudou na interpretação cognitiva das determinadas realidades expostas em estudo.

[...] Naqueles momentos em que identifico em mim interesse, participação, integração, reflexão sobre a realidade real ou virtual, verdadeiras imagens mentais se tornam, assim expressando, geograficamente, "paisagens mentais", ora préidealizadas, ora reais, condizentes com o mundo concreto. Procuro estabelecer esta correlação de uma suposta paisagem mental, porque necessariamente eu não preciso conhecer pessoalmente um determinado lugar com suas características ambientais

\footnotetext{
${ }^{6}$ Tradução livre: "Neste sentido, trata-se de conhecer em última instância, a responsabilidade que deve ser assumida por todos os atores sociais, como apresenta-se hoje, no que se confere a estruturação das sociedades, e as consequências diretas em relação a degradação das paisagens naturais e também das paisagens culturais. [...] Os resultados obtidos apontam a necessidade de uma correspondência entre os aportes da explicação e da compreensão. O diálogo entre as ciências e as humanidades é inevitável no memento de interpretarmos os diferentes espaços que se observam com relação a qualidade de vida material e cultural de seus habitantes. (NAVARRO, [s.d.], p. 9).
} 
físicas, culturais ou sociais para fazer uma idéia de como seja; basta imaginá-lo mentalmente que sou capaz de "sentir" virtualmente o seu cheiro, a sua temperatura, seus sons, seus gostos, suas formas e cores, suas texturas. Assim, tenho a possibilidade de despertar em mim a geração de imagens que auxiliam a compreender uma realidade próxima ou muito distante. Este relato de cenários ou de atores nos dá a dimensão da importância de desenvolver conteúdos, reflexões, análises, na sala de aula ou até mesmo fora dela, que sejam de certa forma significativas para mim ou para cada um que se proponha a aprender e apreender as realidades em que vivemos. Portanto, o conceito geográfico de Paisagem penso estar impregnado desta suposta "paisagem mental" a que me referi e que caracterizei. (LIMA, 2001, p.24).

Logo finalizamos nossas atividades - dia de 31 de Outubro do ano de 2018 - com aplicação de um teste-simulado sobre os diálogos que tivemos dos conteúdos no decorrer de nossos encontros em sala de aula. Objetivando desenvolver certo conflito cognitivo tomamos o teste como auxílio na mediação-comparação com dada realidade desejada. Um auxiliador do processo mais amplo de avaliação, ferramenta esta que usa estas provas como recursos momentâneos para equiparações no processo de aprendizagem escolar (LUCKESI, 2018).

As atividades responsáveis por cumprir com os objetivos da terceira etapa foram: conhecer a especificidade paisagística do contexto regional em que cada bacia hidrográfica citada como conteúdo está inserida. Listar as características físicas, das bacias hidrográficas citadas como temática de conteúdo, tais como extensão e localização geopolítica de fronteira. Localizar o contexto político e econômico de relação sociedade-natureza em que se desdobram as bacias hidrográficas: São Francisco, Amazônica e Tocantins-Araguaia.

Com isso afirmo que para nós estudar a paisagem configurou-se em construir o conhecimento da realidade a partir da compreensão das especificidades socioambientais dos lugares no espaço. Foi estudar a dinâmica socioambiental do espaço geográfico partindo da paisagem disponível em nossa realidade contextual conhecendo o lugar respondendo perguntas que acontece em/no contexto local deste. Realizando assim o tão falado exercício básico da ciência geográfica de estudar o espaço com olhar à relação local-global/global-local. É enxergar na paisagem as contradições e os contrastes que a dialética da totalidade expressa no cotidiano local com a invasão da lógica capitalista globalizada nos lugares com o advento da globalização do meio técnico-científico-informacional. É entender que Verticalidades opõem-se às horizontalidades em "realidade tensa" aonde "cada lugar é, à sua maneira, o mundo". Ao ponto em que podemos "falar de uma cientificização e de uma tecnicização da paisagem" (SANTOS, 2017, p. 334; 2017a, p. 239; 2017b, p. 314). 
[...] Percebe-se que são muitas as dimensões de análise, e que estudar o espaço geográfico, tendo como ponto de partida a paisagem, é muito mais complexo do que normalmente o senso comum considera. É necessário, contudo, que o estudo da paisagem seja profundo e contemple o maior número possível de elementos que a formaram e são responsáveis pelas constantes transformações e pela dinamicidade das mesmas. Ao contemplar o estudo do espaço geográfico, tendo como conceito-chave a paisagem, faz-se necessário levar em consideração a dimensão objetiva e subjetiva da paisagem e o seu processo de construção e reconstrução que são permanentes. [...] É possível permitir que o educando vivencie empiricamente a identificação do seu lugar através do estudo da paisagem. Para isso, é preciso considerar os mais variados elementos que a formam, ou seja, seus diferentes determinantes e dimensões. Para isso acontecer, para o educando ver sentido no estudo da paisagem, é importante trabalhá-la como algo que está presente na vida de cada um, que faz parte da sua história, algo vivo que está em constante modificação pelas pessoas que ocupam aquele espaço e interagem constantemente com ele, e cada um, direta ou indiretamente, ajuda a construir a paisagem que ocupa. (PUNTEL, 2007, p. 289).

Ainda com Puntel (2007, p. 291), entendendo a paisagem enquanto resultado da vida das pessoas em relação à historicidade do lugar, salientamos o fato de que:

[...] Toda paisagem apresenta característica própria, tem forma e marca que resultam da interação da sociedade com a natureza. A visão fisionômica da paisagem é a primeira aproximação da realidade, é a aparência, e cada paisagem cumpre uma função de acordo com as condições próprias do lugar, seja ela estética, política, estratégica, econômica, cultural, histórica, para permitir uma determinada organização e funcionalidade.

A paisagem emerge em nossos trabalhos no processo ensino-aprendizagem escolar de Geografia de forma a promover a compreensão da interação dos elementos socioespaciais (naturais, políticos, econômicos e culturais) no lugar, como conceito capaz de permitir a compreensão da dinâmica de integração dos meios (natural e social) no espaço geográfico. Explicitando neste os traços resultados da essência da relação sociedade-natureza.

Conforme menciona Puntel (2007, p. 286), ao discorrer afirmando que:

[...] Com o objetivo de se tornar significativa a paisagem no ensino e na aprendizagem da Geografia, surge a necessidade de retomar com mais intensidade esse conceito. Ele, se bem conduzido, contribui para uma reflexão e para um entendimento da complexidade da relação entre a sociedade e a natureza, objeto central de estudo da Geografia.

Contextualizando todo este diálogo com Puntel (2007) ao nosso lugar, creio que na mais significativa das considerações deste trabalho, apontamos uma leitura da paisagem do córrego do prata, localizado próximo ao Bairro de Fátima (cidade de Araguaína-TO), às margens da BR-153, conhecido por muitos dos estudantes que participaram das nossas aulas no estágio mas 
também por mim, professor-estagiário, que conheço este lugar pois meus vínculos familiares ancestrais a ele remete minhas raízes genealógicas. Assim como relatado pelos estudantes eu também pude expressar minhas experiências com o córrego do prata tanto de minhas idas lá atualmente como pelas memórias de minha avó que a muito conhece e vivencia experiências com esse lugar e que me diz o quanto mudou de algumas décadas antes do presente para hoje com a introdução do objeto técnico BR-153 sobre o córrego. Que, por sua vez, teve sua dinâmica natural remodelada para nós, gerações do presente, enquanto herança. Pois antes as pessoas banhavam sem o medo de serem atropeladas quando iam acessar as águas do córrego. Ou quando haviam muito mais peixes para pescar do que hoje. Ou quando as águas do córrego não eram poluídas pelo lixo e demais dejetos gerados por pessoas que trafegam nas vias da BR153 com seus veículos automotivos. Eis que o estudo da paisagem apresentou-se no ensino escolar do saber geográfico na ação de decifrar - com emprego e (re)formulação de conceitos para compreensão e inserção da categoria paisagem em nossos estudos - o lugar esperando a obtenção de certa leitura do comportamento da dinâmica socioambiental do dado contexto espacial.

Contudo, as atividades que foram relatadas foram aplicadas objetivando de modo geral: analisar a relação sociedade-natureza como elemento ontológico de construção das paisagens mediante a interação de elementos político-econômicos e culturais. E, de maneira bem mais específica tentando: identificar as características dos diferentes tipos de paisagens a partir do reconhecimento de seus elementos "morfoclimáticos" e "fitogeográficos". Listando as diferentes paisagens regionais consoante a identificação das mesmas e analisando a diversidade de relações que os diferentes povos estabelecem com o uso da paisagem em seus entorno.

Enfim, apresentamos que nosso processo de avaliação - não sendo executada de forma “arbitrária" (LUCKESI, 1994) mas como instrumento de aperfeiçoamento da ação então realizada - consistiu-se em nossa percepção sobre a tomada de consciência que os estudantes desenvolveram sobre sua realidade mediante análise crítica e comparativa dos conteúdos trabalhados em aulas a partir das atividades pedagógicas que foram desenvolvidas durante as aulas, com base relacional, em diálogo entre professor e estudantes enquanto agentes constitutivos do processo ensino-aprendizagem.

Quando, na mais significativa das reflexões, consideramos que o estudo da paisagem em geossistemas propiciaram "a elaboração de cenário sobre as tendências de evolução e dinâmica do espaço geográfico e facilitam a compreensão da natureza pelas comunidades 
humanas, contribuindo para o desenvolvimento duma consciência ambiental" (NASCIMENTO; SAMPAIO, 2004/2005, p. 177). Ao ponto que o estudo ambiental emergiu a partir do estudo dos conteúdos propostos e com subsídio teórico-metodológico da categoria paisagem para tentarmos desvendar o enigma da relação sociedade-natureza. Foi - retomando (e dialogando com) o que apontamos inicialmente - fazer da paisagem um recurso conceitual à interpretação da atual relação que a sociedade tem com a natureza e que está expressa e pode ser apreendida no espaço geográfico perante a leitura de seu(s) sistema(s) ambiental(is).

Entretanto não mais como palco e/ou apenas forma mas como conjunto completamente dinâmico de elementos naturais/sociais atuantes à escrita da história do presente; marcada pela relação que impomos com a natureza a partir do advento da técnica desde histórias pretéritas. Desse modo ressaltamos que a paisagem quando não tida de forma fragmentada (o natural separado do cultural), mas composta pela interação destes e outros múltiplos elementos, nos permite certa compreensão crítica e reflexiva do espaço geográfico com olhar para relação sociedade-natureza impressas na técnica.

\section{ALGUMAS QUESTÕES A SEREM CONSIDERADAS}

Não priorizando o livro didático, buscamos durante nossas aulas leituras investigativas e explicativas em diversos textos, principalmente científicos, que - a partir de uma didática crítica e espacial libertadora - pudessem levar nossos estudantes a uma compreensão de sua realidade apreendendo a totalidade (verdadeiro estudo do universal no local) de seu cotidiano. Muitos lugares e objetos presentes nas paisagens da região foram expostos em fotografias e vídeos para o entendimento destes e exemplificação dos mesmos em nossos estudos.

Ainda assim pergunto se o que ensinamos é geografia física? Hidrografia? Ou seria hidrologia? O que realmente está sendo ensinado em sala de aula aos estudantes da educação básica brasileira? E o livro didático com seus “paleomapas” (CARVALHO, 2010)? Qual seria a alternativa possível? Abdicar da visão unicamente física de descrição do espaço estável seja um primeiro passo importante a ser completado. Com isso possivelmente poderemos desprendermo-nos do pensamento visível de espírito descritivo recorrente sobre a paisagem.

Em embate com a dinâmica espacial (o espaço e sua dinâmica da relação sociedadenatureza perceptível na paisagem) poderemos entender as relações do presente que constroem a paisagem; relações que moldam não apenas os elementos que nós herdamos mas o que 
deixaremos como herança para gerações futuras. Logo cabendo a nós, estudantes e professores, a tarefa de entendermos o agora para vislumbrarmos o futuro a partir de nossas ações; ou melhor, de reflexões críticas destas. Eis que a paisagem promove certa leitura do meio ambiente para conscientização cidadã dos agentes envolvidos no processo ensino-aprendizagem de construção do saber geográfico na educação de ensino escolar. Pois somos parte dinâmica da paisagem e cuidar da natureza das paisagens consiste em cuidarmos de nosso próprio bem-estar. Entendendo o espaço geográfico a partir da compreensão da complexidade relacional sociedade-natureza expressa pelas paisagens como marcas da história.

\section{REFERÊNCIAS}

AB'SÁBER, Aziz Nacib. Os domínios de natureza no Brasil: potencialidades paisagísticas. 7 ed. São Paulo: Ateliê Editorial, 2012.

BERTRAND, G. Paisagem e geografia física global. Esboço metodológico. Raega - O Espaço Geográfico em Análise, v. 8, dez. 2004.

BRASIL. Ministério da Educação. Secretaria da Educação Básica. Base nacional comum curricular. Brasília, DF, 2016.

. Secretaria de Educação e Cultura do Estado do Tocantins - SEDUC. Proposta Curricular do Ensino Médio: versão preliminar. $2^{\circ}$ reimp. Tocantins: SEDUC, 2009.

CARVALHO, M. B. A natureza na geografia do ensino médio. In: OLIVEIRA, A. U. (org.). Para onde vai o ensino de Geografia? 9 ed. 2 reimpr. São Paulo: Contexto, 2010, p. 81-108.

COUTINHO, Maria Tereza da Cunha. Psicologia da educação: um estudo dos processos psicológicos de desenvolvimento e aprendizagem humanos, voltado para a educação: ênfase na abordagem construtivista. Belo Horizonte: Editora Lê, 1992.

CUNHA, L. H.; COELHO, M. C. N. Política e gestão ambiental. In: CUNHA, S. B.; GUERRA, A. J. T. (orgs.). A questão ambiental: diferentes abordagens. $2^{\mathrm{a}}$ ed. Rio de Janeiro: Bertrand Brasil, 2005, p. 43-79.

GOETTEMS, A. A.; JOIA, A. L. Geografia: leituras e interação. $2^{\circ}$ ed. São Paulo: Leya, 2016.

GONÇALVES, C. W. P. A Luta pela Apropriação e Reapropriação Social da Água na América Latina. Observatório Latinoamericano de Geopolítica. 2008. Disponível em: <www.geopolitica.ws>. Acesso em: $14 / 10 / 2018$.

. Os (des)caminhos do meio ambiente. 2 ed. São Paulo: Contexto, 1990. 
LIMA, H. R. O estudo da paisagem no ensino de geografia: uma proposta de abordagem no ensino fundamental e médio. Revista de ensino da escola. Olhares \& Trilhas, v. 2, n. 2, p. 21-32, 2001.

LIBÂNEO, J. C. Didática. São Paulo: Cortez Editora, 2006.

LUCKESI, C. C. Filosofia da Educação. 21ª reimpr. São Paulo: Cortez Editora, 1994.

MARX, K.; ENGELS, F. A ideologia alemã. São Paulo: Expressão Popular, 2009.

NASCIMENTO, F. R.; SAMPAIO, J. L. F. Geografia física, geossistemas e estudos integrados da paisagem. Revista da casa da Geografia de Sobral, Sobral, v. 6/7, n. 1, p. $167-179,2004 / 2005$.

NAVARRO, A. L. La Geografia del paisaje y del medio ambiente: teorias y educacion. Observatório Geográfico América Latina. [s.d.]. Disponível em:

$<$ http://observatoriogeograficoamericalatina.org.mx/egal8/Teoriaymetodo/Teoricos/04.pdf $>$. Acesso em: 23/10/2018.

OLIVEIRA, A. U. Educação e ensino de Geografia na realidade brasileira. In: OLIVEIRA, A. U. (org.). Para onde vai o ensino de Geografia? 9 ed. 2 reimpr. São Paulo: Contexto, 2010, p. $135-144$.

PUNTEL, G. A. A paisagem no ensino da geografia. Ágora, Santa Cruz do Sul, v. 13, n. 1, p. 283-298, jan./jun. 2007.

RUFFINO, P. H. P.; SANTOS, S. A. Utilização do Conceito de Bacia Hidrográfica para Capacitação de Educadores. In: SCHIAVETTI, A.; CAMARGO, A. F. M. Conceitos de bacias hidrográficas: teorias e aplicações. Ilhéus (BA): EDITUS, 2002, p. 111-123.

SANTOS, M. A natureza do espaço: técnica e tempo, razão e emoção. 4 ed. 9 reimpr. São Paulo: EDUSP, 2017.

Do meio natural ao meio técnico-científico-informacional. In: . A natureza do espaço: técnica e tempo, razão e emoção. 4 ed. 9 reimpr. São Paulo: EDUSP, 2017a, p. 233-260.

O lugar e o cotidiano. In: A natureza do espaço: técnica e tempo, razão e emoção. 4 ed. 9 reimpr. São Paulo: EDUSP, 2017b, p. 233-260.

SOUZA, Vanilton Camilo de. Fundamentos teóricos, epistemológicos e didáticos no ensino de Geografia. Revista Brasileira de Educação em Geografia, Rio de Janeiro, v. 1, n. 1, p. 47-67, jan./jun., 2011.

VESETINI, J. W. Geografia crítica e ensino. In: OLIVEIRA, A. U. (org.). Para onde vai o ensino de Geografia? 9 ed. 2 reimpr. São Paulo: Contexto, 2010, p. 30-38. 